\title{
Technologies and Educational Activities for Supporting and Implementing Challenge- Based Learning
}

\author{
Nelson Baloian ${ }^{1}$, Kay Hoeksema ${ }^{2}$, Ulrich Hoppe ${ }^{2}$ and Marcelo Milrad ${ }^{3}$ \\ ${ }^{\mathrm{I}}$ Depto. de Ciencias de la Computación Universidad de Chile, Santiago \\ nbaloianedcc.uchile.cl \\ ${ }^{2}$ Institute for Computer Science and Interactive Systems, \\ University of Duisburg-Essen, Germany \\ \{hoeksema, hoppe\} acollide. info \\ ${ }^{3}$ Center for Learning and Knowledge Technologies (CeLeKT), \\ Växjö University, Sweden \\ marcelo.milrademsi.vxu.se
}

\begin{abstract}
Our Challenge-Based Learning (CBL) method can be described as a special form of problem-based learning, in which the problems are of realistic, open-ended nature. Additionally, CBL contains features of experiential and project-based learning approaches. CBL is supported by the provision of Digital Experimentation Toolkits (DExTs) which comprise materials, initial instructions, references to web resources and specific software tools. Technological challenges lie in the ease of use in accessing these data and in communicating the learners' requests and specifications to the remote sites. Within this article we describe several classroom scenarios for the usage of DexTs in schools. Examples are the calculation of the epicenter of an earthquake, the calculation of lunar heights and the definition of strategies for navigation in a maze. The activities described in this paper were conducted within the framework of our COLDEX project (Collaborative Learning and Distributed Experimentation, http://www.coldex.info).
\end{abstract}

\section{Introduction}

Although computer support for learning was in the early days aimed for the individual learner today we find an increasing number of applications supporting collaborative learning. Collaborative learning has been defined as groups working together for a common purpose. It is hard to explain that the learning theories which are based in the collaborative interaction between learners are entirely responsible for this shift of paradigm. The development of communications, and computer connectivity are certainly also responsible for the shift in the way people work, play,

Please use the following format when citing this chapter:

Balioan, N., Hoeksema, K., Hoppe, U., Milrad, M., 2006, in International Federation for Information Processing, Volume 210, Education for the $21^{\text {st }}$ Century-Impact of ICT and Digital Resources, eds. D. Kumar, and Tumer J., (Boston: Springer), pp. $7-16$. 
and learn. However, authors of systems and methodologies implementing Computer-Supported Cooperative Learning (CSCL) are constantly turning their attention to these theories for inspiring or justifying their work.

Vygotsky's sociocultural theory [1] promotes the importance of social interaction and the use of artefacts for knowledge acquisition. Three principles have been proposed for the design of educational environments derived from Vygotsky's works [2]. First, the notion of authentic activities proposes the modeling of activities and tools derived from professional practices. Second, "construction" refers to learners creating and sharing artefacts within their community. Third, educational environments should be designed to facilitate a close collaboration between learners and their peers as well as between students and experts. Regarding these principles several educational scenarios have been developed within the COLDEX project. The COLDEX project aims at designing innovative learning environments in order to support a wide range of global open learning activities within the scientific domains of astronomy, biodiversity, chemistry and seismology. This goal is achieved by combining an innovative pedagogical approach called Challenge-Based Learning (CBL) together with the support of a variety of modeling tools and experimental scenarios. CBL can be described as extended problem-based learning, but it contains also some components from the experiential, project-based and decision-based learning perspectives.

Project-based and problem-based activities are usually focused on a driving question or problem [3]. In CBL the question or the problem is replaced by a challenge. This challenge is initiated either by the COLDEX project, a teacher or a student group. The assignments or "challenges" to be solved might include ways to develop, design and implement solutions for problems related to scientific phenomena. A meaningful learning activity consistent with CBL is to present learners with a challenge scenario and to ask them to think about a number of possible solutions using a variety of interactive tools. Such an activity serves to centre thinking around meaningful problems and is typically effective in facilitating small-group collaboration. Regarding collaboration, it is important that the need for it is not artificially imposed on the community of learners by the system, but grounded in the nature of the task. Only if collaboration is needed to accomplish the task will learners appreciate the value of, and seriously engage in, collaborative activities such as sharing information and discussing partial research results, and come up with shared decisions and synthetic solutions.

The rest of the paper is divided into four sections. In the next section we present related work to the field of science learning supported by the use of modeling, simulations and visualization techniques. Sections three and four describe the COLDEX scenarios and educational activities we have developed and implemented. Some examples of these activities are described in detail in order to illustrate these ideas. Finally, we conclude this paper by reflecting upon our experiences and presenting some conclusions. 


\section{Related Work}

The CoVis Project [9] aims at supporting "Learning through Collaborative Visualization" that resembles authentic practices of science. It provides a variety of collaboration and communication tools and tries to embed the use of technology in the development of new curricula and pedagogical approaches. It focuses on a project-enhanced science learning pedagogy, scientific visualization tools for open ended inquiry and networked environments for communication and collaboration.

For Edelson [9] authenticity refers to a learning context reflecting the context of use. With respect to this notion of authenticity he characterizes science practice with its attitudes of uncertainty and commitment, discipline-specific tools and techniques, and social interaction. Uncertainty refers to the continual reexamination of techniques and results in the pursuit of unanswered questions. Commitment indicates that this pursuit has meaningful ramifications within the value system of scientists - or students. The use of historically-refined tools and techniques also provides a shared context facilitating communication. And social interaction stresses that scientific work exceeds investigation by including sharing results, concerns and questions among a community of scientists. "A vision of learning that integrates these features of scientific practice has students investigating open questions about which they are genuinely concerned, using methods that parallel those of scientists. Throughout the process, they are engaged in active interchange with others who share their interest."

A synthesis between discovery learning in science and collaborative learning, both supported by computational tools, has recently been suggested by van Joolingen [10]. Indeed, there is a variety of different collaborative activities in discovery learning and collaborative modeling. Bollen et al [11] have identified the following aspects of computer support in collaborative modeling:

- Several students can share a running model by synchronizing their simulation environments.

- The actual model-building process can be shared activity using a modeling language and annotations in shared workspaces.

- Simulations are analyzed to generate hypotheses about the global behavior of systems. To do this in the form of group work, free-hand sketches as well as argumentation graphs and mathematical tools (function plots, tables, etc.) are useful tools.

- Data can be collected in a distributed working mode with different parameters. Shared workspaces allow for gathering data from different groups.

- Group work can be supervised by sharing the environment with a distant tutor.

The "Cool Modes" platform [12] supports these activities by providing a uniform shared workspace environment that allows for constructing and running models with different formal representations (Petri nets, System Dynamics, mathematical graphs etc.) and also supports semi-formal argumentation graphs and hand-written 
annotations. The work reported in this paper has been strongly inspired by these developments.

\section{Classroom Scenarios in the COLDEX Project}

To support educational classroom scenarios according to the Challenge Based Learning approach several so-called "Digital Experimentation Toolkits" (DExTs) have been developed within the COLDEX project. A DExT includes experimental instructions, scientific background information, modeling and simulation tools, access to real scientific data, and the formulation of initial challenges. What we want to provide is an open-ended learning environment that stimulates learners to identify and solve a challenge according to the educational premises of CBL. Interactive tools for modeling and simulation enable learners to generate and try out hypotheses, and show the experimentation results. These DExTs are intended to be handed out to schools to be used in, but not only in, normal school lessons. They provide innovative use of interactive media to enrich the curricula. Teachers should be enabled to integrate these new resources easily in their lessons. As only a few teachers have time to spend on courses or time-consuming studies for learning to use these toolkits, they are mostly self-describing and trouble-free. DExTs are not to be seen as expert systems which present themselves as authoritative and definitive. Our toolkits adopt a more post-modern position on the problems of practice, celebrating difference and providing a democratic form of interaction that allows the user to create and direct instead of being directed. In this sense, they are perhaps best positioned as a means of representing and sharing practice, rather than a way of privately receiving advice on one's own practice [4]. DExTs rely on tools for modeling or simulation and experimentation. The modeling tool is used when the students organise their thoughts early in a Project or when the students are going to design something later on. Different simulation tools are used for testing estimated values and outcomes concerning different influences of events. Our experimentation tools are a prerequisite for the students to construct, visualize and confirm their thoughts in the learning process. Essential for the toolkits is to get access to modeling and collaboration tools, and to a common repository. This is done through the Internet. A small number of remote sites will be established which generate data.

Table 1. Challenge-based learning and other learning methods.

\begin{tabular}{|l|l|l|l|l|}
\hline & $\begin{array}{l}\text { Discovery- } \\
\text { based }\end{array}$ & $\begin{array}{l}\text { Problem- } \\
\text { based }\end{array}$ & $\begin{array}{l}\text { Experiential } \\
\text { learning }\end{array}$ & Challenge-based \\
\hline $\begin{array}{l}\text { Cognitive } \\
\text { focus }\end{array}$ & $\begin{array}{l}\text { Knowledge } \\
\text { inquiry }\end{array}$ & $\begin{array}{l}\text { Knowledge } \\
\text { construction }\end{array}$ & $\begin{array}{l}\text { To grasp and } \\
\text { transform } \\
\text { experience }\end{array}$ & $\begin{array}{l}\text { Knowledge } \\
\text { interpretation, inquiry } \\
\text { and construction }\end{array}$ \\
\hline $\begin{array}{l}\text { Role of } \\
\text { student }\end{array}$ & $\begin{array}{l}\text { Detective, } \\
\text { picking up clues }\end{array}$ & $\begin{array}{l}\text { Participant, } \\
\text { searching }\end{array}$ & $\begin{array}{l}\text { Active participant, } \\
\text { choosing }\end{array}$ & $\begin{array}{l}\text { Active constructor/ } \\
\text { designer }\end{array}$ \\
\hline $\begin{array}{l}\text { Role of } \\
\text { teacher }\end{array}$ & $\begin{array}{l}\text { "As mystery } \\
\text { writer" }\end{array}$ & Coach & Facilitator & $\begin{array}{l}\text { Coach, co-experimenter } \\
\text { and designer }\end{array}$ \\
\hline
\end{tabular}

One conclusion within our classroom scenarios according to the $\mathrm{CBL}$ is a change in the teachers' and students' roles. The students' role gets a stronger focus on being 
a more self- (or group-) regulated "researcher" collaborating by using construction and designing tools. Due to the open-ended scientific nature of the examined research question, the teacher's role focuses more on being a coach or coexperimenter. Table 1 illustrates how CBL differs from some of the other learning methods.

\section{Scenario Examples}

\subsection{The Seismo Scenario}

In this educational scenario, students learn how to analyse earthquakes and to compute and understand some characteristics of the seismic phenomena. For this purpose, a network of six seismographs was installed in different schools of the Metropolitan Region of Chile. When an earthquake occurs, the computers attached to the seismographs generate a file with the seismographic wave. Since every seismograph is located in a different place, they will register different data. By determining the time difference between the first (horizontal) and the second (vertical) hit of the earthquake's wave registered by a single seismograph, the students can determine the distance from the seismograph to the hypocenter, but not the direction. If three or more groups exchange their data and/or results it is possible to define three semi-spheres.

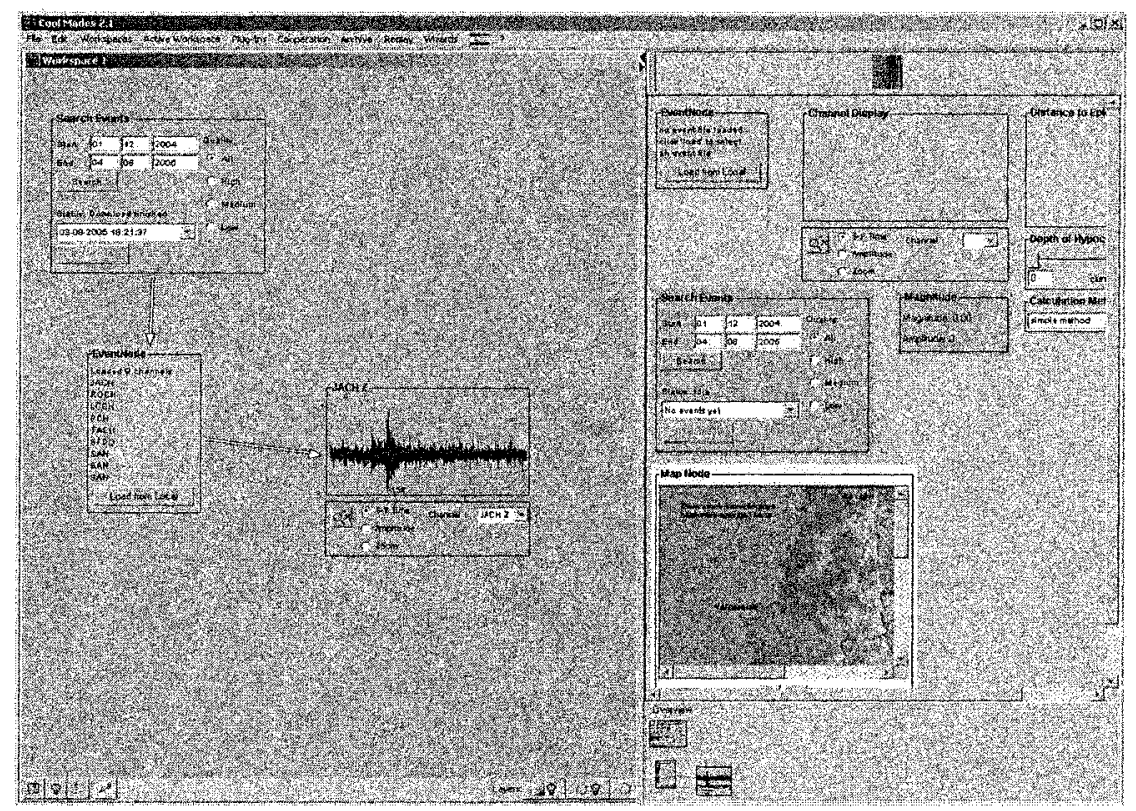

Figure 1: The interface of the Coolmodes seismography palette. 
The point where these semi-spheres intersect each other is the point where the epicenter is located. For enabling students to do these calculations easily, we developed a tool with which they can download the data from a seismograph (which has been previously uploaded by the group of the school where it is located), draw the wave and calculate the time difference between the two hits of the wave, on top of the Coolmodes application (see Section 2).

It provides a working area for this purpose, which is meant to support the workflow of the students' activities. A workflow is represented as a network of different types of nodes, each one implementing a further step towards the calculation of the epicenter. Figure 1 shows the palette with the nodes at the right and the construction of the workflow at the left. Nodes can be created and placed in the working area by "drag-and-drop" from a palette of different node types.

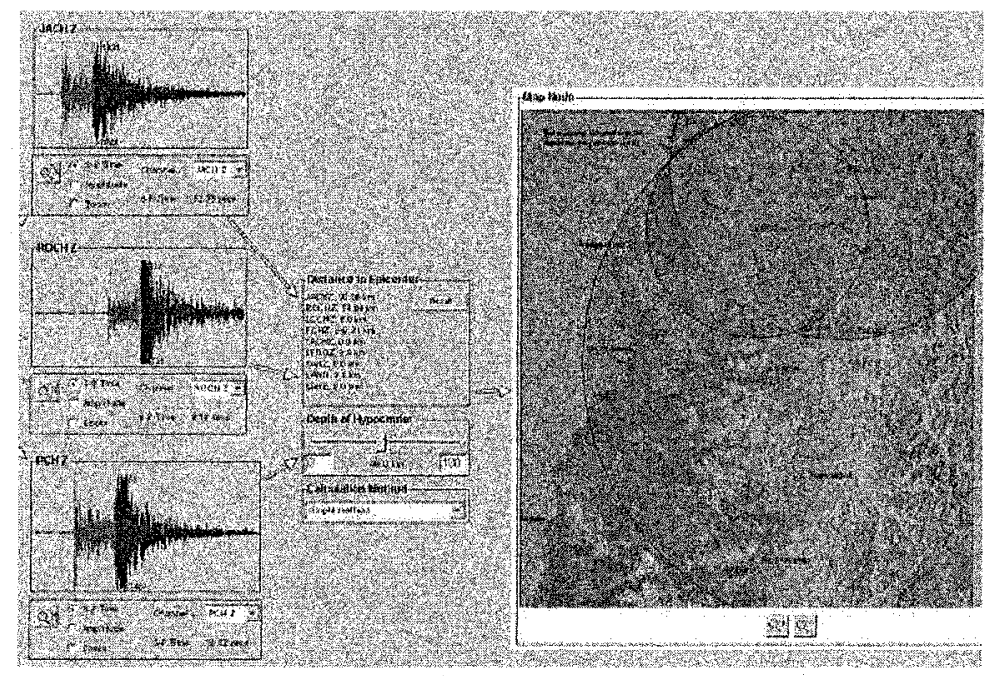

Figure 2: The slide bar of the center's node changes the estimated depth of the hypocenter.

Adding an edge between two nodes transfers output values of one node as input values for the successor, but of course, this is allowed by the system only between nodes where this operation makes sense. On the node containing the map, circles representing the calculated distance from the sensors are drawn (see Figure 2). By changing the supposed depth of the earthquake's genesis location (called hypocenter) the diameter of those circles also changes. The point where they all intersect is the location of the epicenter. This setting allows various kinds of collaborative learning activities.

\subsection{The Moon Scenario}

Within our astronomy scenario the students are enabled to calculate lunar heights by using moon images taken by themselves or retrieved from a repository via the 
internet. Within the COLDEX project we have access to several different-sized telescopes in Europe and South America (Chile). All the telescopes are remote controllable and accessed through web services so there is no change needed on the client side software when choosing another telescope. To calculate lunar heights, the students need to be able to model calculation networks. Mathematical backgrounds are the sentence of three and the theorems of similar triangles. In a first step they have to discover the needed relationship between several measurements (crater shadow length, distance crater-terminator,) by using a dynamic 2D-geometry model. After deciding how to proceed they can take measurements out of their moon image using a special measurement tool (e.g., including zooming) storing the measured values automatically into produced input nodes in the same (possibly network shared) workspace. The students then can calculate the lunar heights by using a visual language to define calculation networks. Fig. 3 shows the measurement tool and a calculation network having the taken measurements as inputs.

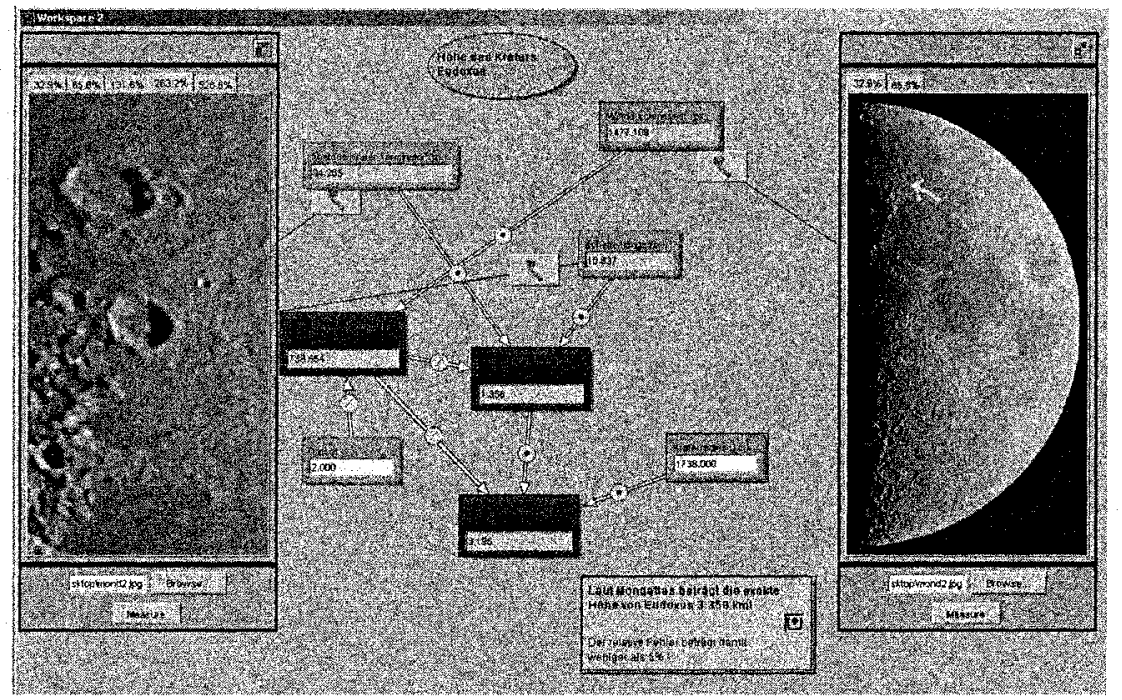

Figure 3: The lunar heights calculation

Several competitive or cooperative scenarios using the described environment are possible. Within a collaborative school project "building a moon lexicon" one chapter could be about the biggest mares and highest or deepest craters. Therefore tasks could be distributed like:

- developing the needed formula / calculation network

- producing / retrieving moon images (When to take? Which are the best?)

- working on different areas of the moon

An example of a competitive scenario using the described environment could be a "moon measuring contest". At the beginning of the contest students get access to the dynamic geometry model, to the telescope image repository and to the names of the craters which are part of the contest. Within a predefined time limit they have to understand the calculation principle and to measure the heights of the craters as exact as possible to them. Therefore they could, e.g., use different images, process their images and build the averages out of their results. The effectiveness of such group 
work will be related too how the students distribute the different parts of the work within their groups. This could be a focus of the following discussion. A more detailed scenario description can be found at [5].

\subsection{The Maze Scenario}

The leading challenge within this scenario is to define a maximally-general strategy to let a robot escape from a maze. Although this question has its own history [6], the parallelism to the little (at least partially) autonomous acting robots sent to Mars over the last years also inspired us within COLDEX to create this scenario. The robot "senses" its direct neighbourhood (free or wall in front, to the right or to the left) and searches for a given rule how to behave in this situation. A very easy to implement strategy is "wall following", which will not assure the escape out of mazes with "islands". These can be solved by more sophisticated algorithms using additional information (absolute heading). A special feature in our scenario is the possibility of "reactive programming-by-example". The robot has to react to the current situation description. It starts with an empty memory. In a situation to which no existing rule applies, the user/learner will be prompted to enter a new action. Each user-defined reaction will be added to the memory as a rule which will be applied under the same circumstances. Rules can be generalised by replacing concrete elements of situation descriptions by jokers which would match any value.

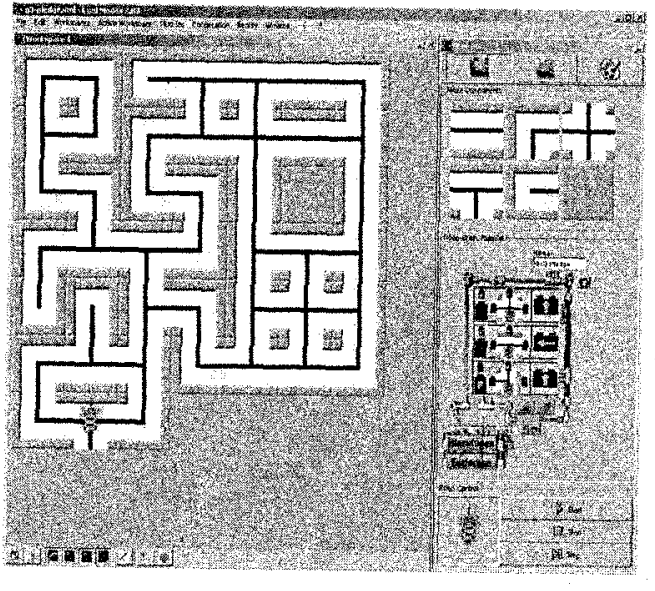

Figure 4a

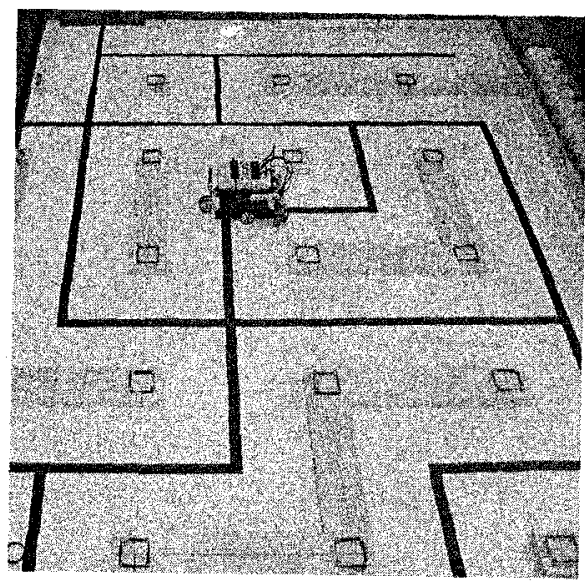

Figure 4b

The user will react only by defining actions in concrete situations without having to define global control strategies (local reactive programming). Our maze scenario consists of physical (wooden maze, RCX-driven Lego Mindstorms robot, communication via PDA or PC, see Fig. 4a) and virtual environments (software plug-in for our Cool Modes environment [7], see Fig. 4b, and a tiny PDA environment). Developed rule sets can be stored in and retrieved from a local server within a WLAN. This scenario fits, e.g., for competitive group work building a maze the other groups' robots cannot deal with / developing rule sets to be able to 
escape from the other groups' mazes. A more detailed scenario description can be found in $[8]$.

\section{Experience and Conclusions}

The principles, methodologies and tools described in this paper have been successfully used in real scenarios in schools located in different countries. So far, about 40 teachers and 200 students haven been involved in usage scenarios ranging from short-term activities of a few days and longer-term activities over a whole school year in which COLDEX DExTs supported parts of an integrated science curriculum. Many of the interesting learning products have been fed into a common repository. Since these learning products originate from the same basic challenges and since they have been elaborated using the same set of tools, it is quite straightforward to exchange and share these between different learning groups or individuals. The COLDEX repository is directly connected to the Cool Modes learning environment supporting upload with automatic indexing as well as similarity-based retrieval with given examples. Beyond the provision of tools and challenges, this community repository is another feature of the COLDEX approach to learning which has been explained elsewhere in more detail [13]. The evaluation of the COLDEX scenarios presented in this paper took place in several countries using generic evaluation instruments in order to be able to provide the same evaluation possibilities for all scenarios. We created a quantitative basis using questionnaires and analyzed qualitative data eliciting contextual and scenario specific information. The instruments were adapted and tailored to the collaborative and technological nature of COLDEX scenarios. Different types of evaluation were conducted in order to assure appropriateness of the evaluation results. Based on the results from our evaluation [14], the COLDEX project has been successful in creating innovative educational scenarios and supporting authentic scientific activities mediated by advanced learning technologies. These results provide some indications that show that students have become more interested and involved in science learning when these tasks can be supported by authentic scientific inquiry activities, done in collaboration with other peers and supported by multimodal interaction. The results of the different experiences conducted within COLDEX have been gathered in Sweden, Germany, Chile and Colombia and they can be summarised as follows:

- Teachers have been able to adapt and apply the tools to their situational needs very flexibly and creatively. Several additional suggestions and materials have been proposed and elaborated by teachers.

- Students have been able to operate the tools with ease. Although this is not ideal, it has been possible to work through the moon scenario within half a day under strong time constraints. We have seen many cases of creative coconstruction with high quality results.

- Teachers have responded very positively to the community repository which was only provided in the last phase of the project. They clearly saw the added value of sharing learning results in the nonstandard domains of COLDEX. 


\section{Acknowledgments}

This work has been partially supported by the European Community under the Information Society Technologies (IST) program of the 5th Framework Program for RTD - Project COLDEX, contract IST-2001-32327. This document does not represent the opinion of the European Community, and the European Community is not responsible for any use that might be made of the data appearing therein.

\section{References}

1. Vygotsky, L. S. (1978). Mind in society: the development of higher psychological processes. Cambridge: Harvard University Press.

2. Bellamy, R.K.E. (1996). Designing Educational Technology: Computer-mediated Change. In B. A. Nardi (Ed.), Context and Consciousness: Activity Theory and Human-ComputerInteraction (pp. 123-146). Cambridge, Massachusetts: MIT Press.

3. D.H. Jonassen (1999). Designing Constructivist Learning Environments, Ch. 10 in Instructional-Design Theories and Models: A New Paradigm of Instructional Theory, vol. II. C.M. Reigeluth (ed.) Mahwah, NJ: Lawrence Erlbaum Associates.

4. Beetham, H (2002). Developing learning technology networks through shared representations of practice. In Rust, C (Ed) (2002) Improving student learning through learning technologies. Oxford: Centre for Staff and Learning Development.

5. K. Hoeksema, M. Jansen, U. Hoppe: Interactive Processing of Astronomical Observations in a Cooperative Modelling Environment. In Proceedings of IEEE, ICALT 2004. Joensuu, Finland.

6. Abelson, H. and A. diSessa, Turtle Geometry, MIT Press, Cambridge (USA), 1982.

7. Pinkwart, N. (2003). A Plug-In Architecture for Graph Based Collaborative Modeling Systems. In: Proc. of AIED 2003, pp. 535-536. Amsterdam, IOS Press.

8. M. Jansen, M. Oelinger, K. Hoeksema, U. Hoppe (2004). An Interactive Maze Scenario with Physical Robots and Other Smart Devices. In: Proc. of WMTE 2004, Los Alamitos, California (USA), pp 83-90.

9. Edelson, D.C. (1997). Realising Authentic Science Learning through the Adaptation of Scientific Practice. In Tobin, K \& Fraser, B. International Handbook of Science Education. Dordrecht, NL: Kluwer.

10. Joolingen, W. R., van (2000). Designing for Collaborative Learning. In G. Gauthier, C. Frasson \& K. VanLehn (Eds.) Intelligent Tutoring Systems, $5^{\text {th }}$ International Conference, Montréal, Canada. Berlin: Springer.

11. Bollen, L., Hoppe, H.U., Milrad, M. \& Pinkwart, N. (2002). Collaborative Modelling in Group Learning Environments. In Davidsen et al. (eds), Proceedings of the XX International Conference of the System Dynamics Society. Palermo (Italy), July 2002.

12. Pinkwart, N., Hoppe, H. U. \& Gaßner, K. (2001). Integration of Domain-Specific Elements into Visual Language Based Collaborative Environments. In M. R. S. Borges, J. M. Haake \& H. U. Hoppe (Eds.), Proceedings of the $7^{\text {th }}$ International Workshop on Groupware, CRIWG 2001.Darmstadt, Germany, 6-8 September 2001. IEEE CS Press.

13. Hoppe, H.U., Pinkwart, N., Oelinger, M, Zeini, S., Verdejo, F., Barros, B. \& Mayorga, J.I. (2005). Building Bridges within Learning Communities through Ontologies and "Thematic Objects". In Proceedings of the International Conference on Computer Supported Collaborative Learning (CSCL2005), Taiwan, June 2005.

14. Björn, M., Karlsson, M., Wichmann, Astrid., Otero, Nuno., Milrad, Marcelo., Oelinger, Maria. \& Hoppe, Ulrich. (2005) 'COLDEX, Final Evaluation Report', in Information Society Technologies (IST) EU Program, Project No.: IST-2001-32327, Deliv. No. D.8.3.1. 